\title{
ENTRE O ACONTECIMENTO E A MEMÓRIA: DISCURSOS SOBRE O PAPA FRANCISCO EM CAPAS DE REVISTA DE GRANDE CIRCULAÇÃO
}

\author{
Fabio Elias Verdiani Tfouni* \\ Universidade Federal de Sergipe \\ Departamento de Letras \\ Itabaiana e Aracaju, SE, Brasil \\ Anderson de Carvalho Pereira ${ }^{*}$ \\ Universidade Estadual do Sudoeste da Bahia \\ Departamento de Ciências Humanas, Educação e Linguagem \\ Itapetinga e Vitória da Conquista, BA, Brasil
}

\begin{abstract}
Resumo: Este trabalho realiza uma análise dos discursos sobre o Papa Francisco em capas de revista nacionais e internacionais de grande circulação. Discutimos se a escolha do novo papa, e os discursos advindos dela, podem ser considerados acontecimentos. Trabalhamos a questão do acontecimento relacionado este com a memória, como é próprio da análise do discurso pêcheutiana. Argumentamos que os efeitos de sentido criados sobre o novo papado se relacionam com a sua caracterização como um acontecimento. Também analisamos a espetacularização do Papa na mídia e outros aspectos, como a questão da interpretação do discurso pedagógico e da relação com o populismo.
\end{abstract}

Palavras-chave: Acontecimento. Memória. Discurso. Mídia. Papa Francisco.

1 INTRODUÇÃO

A escolha do novo papa em 2013 tem sido tratada como uma grande novidade nas ruas, nas conversas do cotidiano e, fundamentalmente, pela mídia. O objetivo deste artigo é analisar os discursos sobre o papa Francisco e seu papado tal como veiculado pela mídia, mais especificamente, em capas de revista. Parte dessa análise reflete a questão do "novo", tentando ver o que há de novidade (e se realmente há alguma) no novo pontificado e o que continua como antes. Iniciamos esta discussão sinalizando que grande parte dos sentidos produzidos sobre o novo papa está relacionada a essa novidade veiculada pela mídia.

\footnotetext{
* Doutor em Letras pela Universidade Estadual Paulista Julio de Mesquita Filho. Professor adjunto. Tem estágio de Pós-doutorado no IEL/UNICAMP com bolsa FAPESP. Email: fabiotfouni@hotmail.com

** Doutor em Psicologia pela Universidade de São Paulo, com estágio na Universidade de Paris XIII. Atualmente, Professor Adjunto. Foi professor visitante na Universidade Nacional de Córdoba (Argentina), em 2015. Email: apereira.uesb@gmail.com
} 
Para introduzir essa questão, diremos que a novidade guarda uma forte relação com o conceito de acontecimento discursivo. Cabe, então, perguntar: o lugar discursivo "sujeito-papa" pode ser visto como um verdadeiro acontecimento histórico, que clama por interpretação no sentido que a Análise de Discurso francesa (doravante, AD) dá a esse termo? A partir desta questão principal, discutimos por quais vias da memória discursiva os efeitos de sentido sobre o sujeito-papa sustentam sua visibilidade pública. Este caminho interessa à proposta pêcheutiana (PÊCHEUX, 1999) no que se refere ao reconhecimento social, vislumbrado nos termos de um acontecimento discursivo.

\section{ASPECTOS TEÓRICOS: ACONTECIMENTO E MEMÓRIA}

Em AD, a discussão sobre o acontecimento discursivo indica, grosso modo, um efeito de interpretação de "novidade". Este efeito está sustentado pelo modo com que Pêcheux revisitou sua principal obra Semântica e Discurso: uma crítica à afirmação do óbvio (1993) e retomou uma discussão sobre a relação do interdiscurso com o conceito de pré-construído, por meio da noção de memória discursiva e de acontecimento discursivo.

As reflexões sobre acontecimento e memória discursiva possibilitam um debate sobre o efeito de sentido sustentado na veiculação de imagens sobre o papa Francisco. Pêcheux (1999, p. 50) dialoga ao mesmo tempo com um duplo vértice sobre a relação entre memória e acontecimento discursivo; em suma, essa "inscrição do acontecimento no espaço da memória" transborda levando a uma "dupla forma-limite" de um espaço de tensão, tanto ao escape à regularidade inscrita, quanto à absorção, como não ocorrida. Em seguida, o autor faz uma ressalva: "o fato de que possa existir localização de traços distintivos e de oposições pertinentes na esfera do icônico" (PÊCHEUX, 1999, p. 51).

Adiante, a relação do icônico com a memória provoca interrogações, provoca questões, diz Pêcheux (1999, p. 51):

\footnotetext{
essa negociação entre o choque de um acontecimento histórico singular e o dispositivo complexo de uma memória poderia bem, com efeito, colocar em jogo a nível crucial uma passagem do visível ao nomeado, na qual a imagem seria um operador de memória social, comportando no interior dela mesma um programa de leitura, um percurso escrito discursivamente em outro lugar: tocamos aqui o efeito de repetição e de reconhecimento que faz da imagem como que a recitação de um mito.
}

Deste modo, indagamos: De que maneira a memória discursiva cria efeitos de oposição em torno de um ícone transformado em "mito individual" pela imprensa e quais efeitos de sentido provoca para seu reconhecimento? Na linha do que propõe Pêcheux (1999, p. 52), qual a natureza dos implícitos restabelecidos por essa leitura da mídia e que condições fornece para ser considerada legível, ou seja, como "acontecimento a ler"?

Começamos notando que a escolha de Jorge Bergoglio para papa, agora chamado de papa Francisco, é um fato que se destaca entre outros fatos de 2013. Isso pode ser visto como um indício de acontecimento histórico que desencadeia um acontecimento discursivo? Isto porque esse destaque de 2013 confere ao papa recém-eleito o título de "homem do ano" por algumas revistas. 
O acontecimento a ser lido restabelece implícitos e pré-construídos localizáveis, que se tornam legíveis sob efeito da memória discursiva. Como se percebe, há um efeito paradoxal no primeiro caminho. Qual seja, para alcançar "a condição do legível" deve-se partir em direção do "próprio legível”. No caso em questão, vamos analisar de que modo, no diálogo entre as manchetes veiculadas nas capas de revistas, este efeito paradoxal de todo mecanismo ideológico se sustenta apagando as pistas, os rastros, que são condição de leitura para que tal efeito mesmo se estabeleça.

Todo discurso é ideologicamente marcado. Assim, para a análise do discurso a materialidade da ideologia é o discurso e a materialidade do discurso é a língua (ORLANDI, 1996). Os discursos midiáticos tendem a fornecer ao leitor uma versão construída a partir de sentidos naturalizados.

É assim que lemos em Charaudeau: “[...] o universo da informação midiática é efetivamente um universo construído. Não é, como se diz às vezes, o reflexo do que acontece no espaço público, mas sim, o resultado de uma construção.” (2007, p. 150).

Nesse sentido, podemos dizer que todo discurso é uma construção sobre um suposto real. E que o que chega aos sujeitos é sempre um discurso sobre o real e nunca o real em si mesmo. Pretendemos, então, compreender quais discursos, quais efeitos de sentido e quais imagens sobre o papa Francisco as capas de revista aqui analisadas constroem para o sujeito-leitor.

Em seguida, apresentamos a análise feita conforme as contribuições de Serrani (1997) acerca da noção de sequências discursivas a serem elencadas a partir do recorte de uma questão determinada (no nosso caso, a relação entre acontecimento discursivo e memória). O recorte principal que norteia nossa investigação sobre este jogo de sentidos pauta-se no efeito de novidade; foi a partir deste recorte que apresentamos a análise de doze sequências discursivas (doravante, SD) e onze figuras retiradas de diferentes capas de revistas de circulação periódica, no Brasil e ao redor do mundo. A SD engloba uma parte da materialidade linguística (palavra, enunciado ou conjunto de enunciados) referente à eleição de uma zona de sentido específica sobre a qual se debruçou a questão teóricoanalítica; lembrando que para a $\mathrm{AD}$ o conceito de enunciado é diferente do conceito de frase ou proposição tal como formulados pela linguística ou pela filosofia.

Reforçando o que afirmamos acima e, introduzindo a análise, diremos que o acontecimento discursivo pode ser tratado como um evento histórico suficientemente relevante para que seja registrado. Assim, há eventos mais importantes e menos importantes.

\footnotetext{
Nesse sentido, o acontecimento histórico "consiste em um fato que, por sua relevância enquanto ocorrência no mundo, passa a ser rememorado na história, fazendo parte do dizer sobre o passado de um povo, narrado pela ciência histórica" (LE GOFF, 1996 apud DELASILVA, 2008). Em outras palavras, o fato deve ser suficientemente significativo para ser relembrado ou ser registrado em livros, fazendo parte da história de um povo, de uma sociedade, uma comunidade, como reflexo da cultura. (RASSI, 2012, p. 44)
} 
O acontecimento discursivo também pode ser visto como um evento que rompe com "o que vinha antes", instaurando uma nova ordem e novos dizeres. Mas não sem uma relação com a memória, como já dissemos. Sobre isso, Indursky afirma:

\begin{abstract}
Quando um acontecimento discursivo sucede, instaura-se uma relação tensa tanto com a memória (que tenta inscrevê-lo na ordem da repetibilidade, [...]) quanto com o discurso novo, inaugural, que rompe com a ordem da repetibilidade, construindo um novo sentido possível para o enunciado. (INDURSKY, 2003, p. 107, grifo da autora)
\end{abstract}

A partir dos conceitos de acontecimento histórico e discursivo, argumentamos aqui que a escolha do novo papa pode ser tratada tanto no sentido de acontecimento histórico como no de acontecimento discursivo.

Existe no período recente um imaginário de progressismo em torno de algumas decisões da Igreja Católica, conforme aponta Vincent (1997). Dentre estas decisões, inclui-se um tipo de sensibilidade para a miséria do chamado Terceiro Mundo da qual decorreram o Conselho Episcopal Latinoamericano (CELAM) e as Conferências de Medelín, Kampala (África) e Manila (Ásia) em que a miséria social e moral despertaram culpa social, na era de João Paulo II em 1985. Esta sensibilidade configurou um embate entre o predomínio do núcleo conservador do CELAM, entre 1972 e 1979, e o retorno em 1985 de João Paulo II à América Latina, em que "denuncia as injustiças sociais insuportáveis" e declara-se favorável a uma "Igreja dos Direitos Humanos fiel à sua opção preferencial pelos pobres", ao preconizar "uma nova evangelização", mas que não deixa de alertar contra as "contaminações marxistas" (VINVENT, 1997, grifos do autor, p. 415). Pouco adiante o então cardeal Ratzinger afirma que é errôneo opor pão e palavra ou mesmo privilegiar um diante do outro, de tal sorte que "empréstimos acríticos da ideologia marxista e o recurso às teses de uma hermenêutica bíblica marcada pelo racionalismo estão na base da nova interpretação, que vem corromper o que havia de autêntico no generoso compromisso social em favor dos pobres" (declaração de Ratzinger, de dezembro de 1985, apud VINCENT, 1997, p. 418). É este lugar da memória discursiva que sustenta as condições de produção dos discursos produzidos pelas revistas de grande circulação que faz parte de nosso dispositivo teóricoanalítico.

Com base em Orlandi (2002), notamos que na análise do discurso existe uma relação bastante próxima entre teoria e análise, na medida em que uma ecoa sobre a outra. Desse modo, para analisar um corpus, o analista frente à questão que formula escolhe o conjunto de conceitos com os quais vai trabalhar na análise, para responder à sua questão. Assim, o analista monta um dispositivo de análise a partir do conjunto da teoria (dispositivo teórico).

Podemos afirmar que a escolha do corpus é guiada por uma questão principal da qual decorrem formulações teórico-analíticas a respeito da sua organização. No caso, nossa pré-seleção das imagens de capas de revistas foi inicialmente organizada em função da pergunta sobre se há acontecimento discursivo em torno do modo de se enunciar sobre o novo papado e qual a natureza do funcionamento deste acontecimento; seu alcance, sua base de sentido. Deste modo, o foco principal não foi a organização cronológica (o que configuraria uma análise sobre o acontecimento histórico mais detidamente), mas a circulação de sentidos, a qual se fundamenta na retomada do já dito. 
Assim, neste trabalho, buscamos na mídia materiais através dos quais pudéssemos mobilizar o conceito de acontecimento discursivo e, inevitavelmente histórico, na medida em que todo acontecimento discursivo é histórico. Lembrando que o acontecimento discursivo tem relações com outros conceitos da AD como ideologia, posição ideológica, posição sujeito, e outros. Essas questões entram aqui mas não constituem o foco central deste trabalho. O foco aqui é o conceito de acontecimento discursivo. As questões relativas à ideologia, à posição sujeito e outras serão alvo de trabalhos futuros. Conforme Orlandi (2002, p. 27):

\footnotetext{
Cada material de análise exige que seu analista, de acordo com a questão que formula, mobilize conceitos que outro analista não mobilizaria, face a suas (outras) questões. Uma análise não é igual à outra porque mobiliza conceitos diferentes e isso tem resultados cruciais na descrição dos materiais. Um mesmo analista, alias, formulando uma questão diferente, também poderia mobilizar conceitos diversos, fazendo distintos recortes conceituais.
}

Para a análise do discurso não existe descrição "neutra" do corpus, toda descrição já é uma interpretação. Assim, para a análise do discurso, não é possível fazer um recorte do corpus que já não possua, de antemão, alguma pergunta teórica que vai guiar a análise, mesmo que isso seja considerado um procedimento não desejado em disciplinas que adotam um modelo positivista ou empirista de conhecimento.

\section{ANÁLISE DO CORPUS}

A partir destas considerações, podemos afirmar que não utilizamos como critério para a seleção das capas de revista aqui analisadas seu pertencimento à revista $\mathrm{X}$ ou $\mathrm{Y}$, nem à posição ideológica das revistas, uma vez que, sabidamente, os meios de comunicação se filiam a certos discursos e a certas ideologias. A decisão para a escolha do corpus se baseou na possibilidade das capas e seus enunciados serem mobilizados a partir do conceito de acontecimento discursivo.

Em termos de acontecimento histórico, notamos que a escolha do novo papa é tratada pela mídia como um assunto de extrema importância, que por isso deve ser registrado e ficar na história. Em termos do acontecimento discursivo, investigamos se a escolha do novo papa permite a instauração de novos sentidos e novos dizeres sobre a Igreja Católica, sobre o papa e sobre o que é ser papa; em suma, sobre a posição-sujeito papa e o que se pode ou não dizer e fazer nessa posição. Isso inclui analisar um jogo de imagens que permite uma antecipação (imaginária) dos novos dizeres do/sobre o papa. Nesse contexto temos a figura 1, capa da revista Rolling Stone do dia 13 de fevereiro de 2014, que traz nossa SD1. 


\section{Figura 1 - SD1: "The times they are a-changin"”}

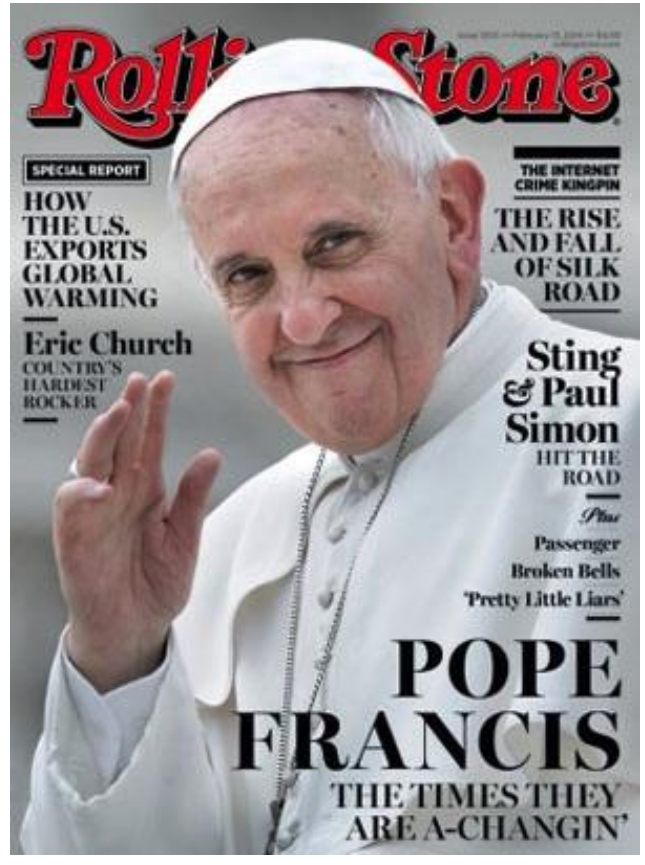

A SD1 indica que a escolha do novo papa e seu novo papado é um acontecimento histórico sem precedentes que traria uma descontinuidade, ou seja: uma mudança radical na história, operando um rompimento com as concepções sobre a Igreja e seu papel no mundo.

Não se esperaria a figura papal na capa de uma revista como a Rolling Stone, o que, de início, já marca uma quebra da expectativa na memória que temos da imagem do papa e, ao mesmo tempo, isso se constitui num novo dizer, num enunciado que traz o rompimento com a memória sobre o papa, mas retoma uma outra memória que vem da cultura popular, mais especificamente a música americana.

$\mathrm{O}$ enunciado The times they are a-changin é a faixa título de um LP lançado por Bob Dylan em 1964, que cantava sobre as transformações sociais e políticas pelas quais o mundo passava. Nos Estados Unidos isso se materializou com os movimentos estudantis, movimentos negros, movimentos pelos direitos civis. Haveria um deslizamento de sentidos num tom metafórico, colocando que o novo papa seria o agente de mudanças, trazendo uma nova era, ou novos tempos.

Com isso temos a retomada de um enunciado que já circulava anteriormente (nos anos 60) com um sentido específico e que, agora, passa para outro lugar ganhando novos sentidos. É por essa via que Pêcheux $(1997,1999)$ e Indursky $(2003)$ colocam a questão da tensão entre acontecimento discursivo e memória.

No ano de 2013, especificamente, por esta importância e pelo alcance dos seus feitos (passados ou projetados para o futuro), a revista Time, edição de 23 de novembro de 2013 (Figura 2), apresentou o papa como "pessoa do ano". Essa é nossa SD2: 


\section{Figura 2 - SD2: POPE FRANCIS. PERSON OF THE YEAR}

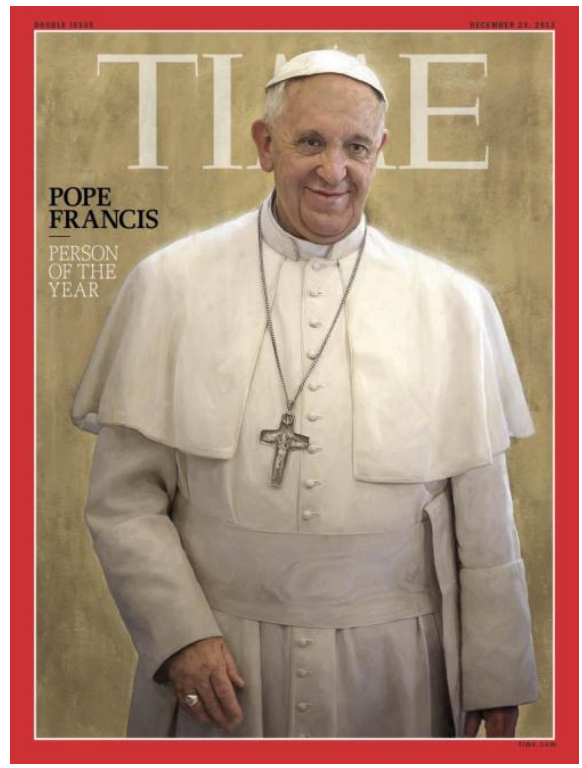

Nas figuras 1 e 2 (SD1 e SD2) vemos o destaque, o efeito de novidade e de acontecimento discursivo recaírem sobre a figura do papa e não sobre a Igreja; trata-se então de um discurso "personalista" que coloca a pessoa-papa como agente de mudança, silenciando (ORLANDI, 1995) que ninguém governa sozinho, nem o papa, e que, portanto, os acontecimentos históricos são produtos de ações sociais e não de uma única pessoa, por mais proeminente que essa pessoa seja.

Como já dissemos, o papa merece lugar de destaque, na medida em que seu papado já desde o início parece ser tratado pela mídia como um acontecimento histórico. O caráter histórico deste acontecimento se justificaria pela singularidade da eleição do novo papa. Alguns pontos dessa singularidade são: o Papa anterior, Bento XVI, renunciou, sendo que tal fato a Igreja Católica não se via desde o papa Gregório XII, em 1415; o papa Francisco é o primeiro papa da América latina; é o primeiro papa jesuíta. Mas seria isso suficiente para caracterizar o novo papado como um acontecimento, entendido como uma ruptura com o já dado e com o cristalizado? Pelo que temos visto na mídia, esses aspectos do novo papado já bastariam para caracterizá-lo como um acontecimento histórico. $\mathrm{O}$ acontecimento é algo que sempre clama por uma cobertura jornalística e, a grandiosidade do fato causa interesse e gera condições para a espetacularização do papa e da Igreja.

A este respeito, vale notar que um marco na exibição pública dos papas da Igreja Católica veio com o aparecimento de Carol Woytyla (papa João Paulo II), quando este sofreu uma tentativa de assassinato. Naquela ocasião, começaram a aparecer projeções midiáticas do papa não vistas até então. No Brasil, esta repercussão no plano imaginário circula em uma música, a saber: "O papa é pop/O papa levou um tiro à queima roupa/ o pop não poupa ninguém”. Começa, então, uma nova circularidade sobre a veiculação da imagem pública do pontífice. O efeito de espetáculo decorrente deste evento público faz notar aquilo que Debord (2007) chama de sociedade do espetáculo. 
No caso do papa, sua projeção pública é marcada desde o uso do nome (não correspondendo ao nome civil), mas em sintonia com as tradições e os cânones da Igreja Católica.

Uma dessas promessas de um novo tempo é a de um papa voltado para o povo e para os pobres. Porém, um papa voltado para o povo não é mesma coisa que um papa voltado para os pobres. A este respeito, vejamos a figura 3, publicada na revista Time do dia 29 de julho de 2013, a qual traz nossa SD3:

\section{Figura 3 - SD3: The people's Pope}

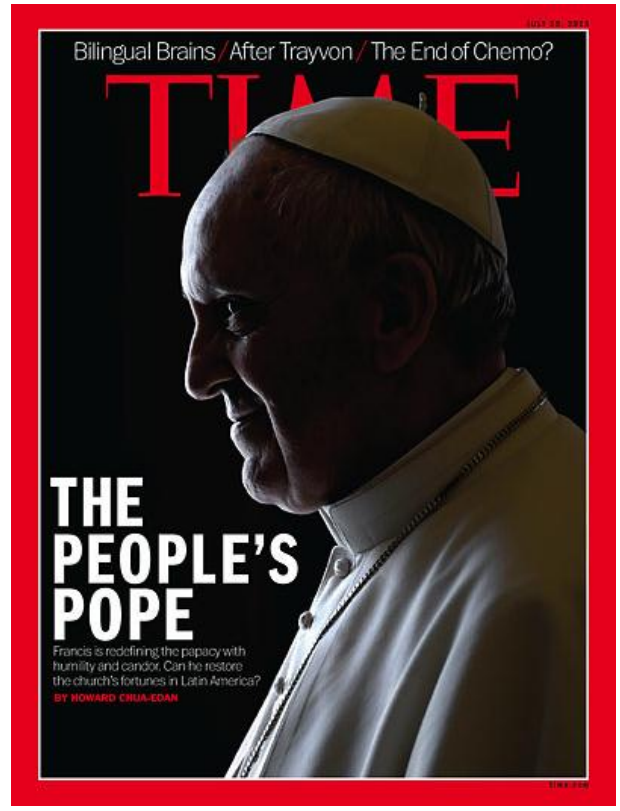

Se o acontecimento discursivo é uma novidade, é porque ele se relaciona por contraste, por diferença, com a memória que se tem de algo até então. Nesse sentido, o papa atual seria "o papa do povo", por contraste, e por destoar do que tem sido a imagem e a atitude da Igreja Católica até então. Se "este" é o papa do povo, é porque os outros não são ou não eram: eis o contraste. Nesse sentido, boa parte dos discursos e efeitos de sentido sobre o novo papa não são compreensíveis (de acordo com o conceito presente em ORLANDI, 2002, p. 26) sem levarmos em conta o aspecto de acontecimento, de novidade presente neles. A figura 4, na página seguinte, capa da Revista Veja $\mathrm{N}^{\mathrm{o}} 2331$, de Julho de 2013, por sua vez, traz o enunciado (SD4) "O papa dos pobres".

A SD4 traz o termo "pobres" ao contrário da SD3, que usa o termo "povo". Não seria o papa do povo, seria o papa dos pobres. Qual o sentido de "papa dos pobres"? Existe um lugar da memória discursiva segundo o qual a Igreja Católica se preocupa com os pobres, promovendo a caridade, dando a eles a prioridade no reino dos céus (lembramos os provérbios "os últimos serão os primeiros" e "quem dá aos pobres empresta a Deus", por exemplo). Este lugar faz alusão àquilo que Althusser (1999) aponta acerca de um efeito ideológico da "administração" da pobreza em consonância à naturalização da reprodução da desigualdade das condições de produção. 
Figura 4 - SD4: 0 papa dos pobres. 0 significado de ter Francisco entre nós em um momento explosivo para a Igreja Católica e para o Brasil

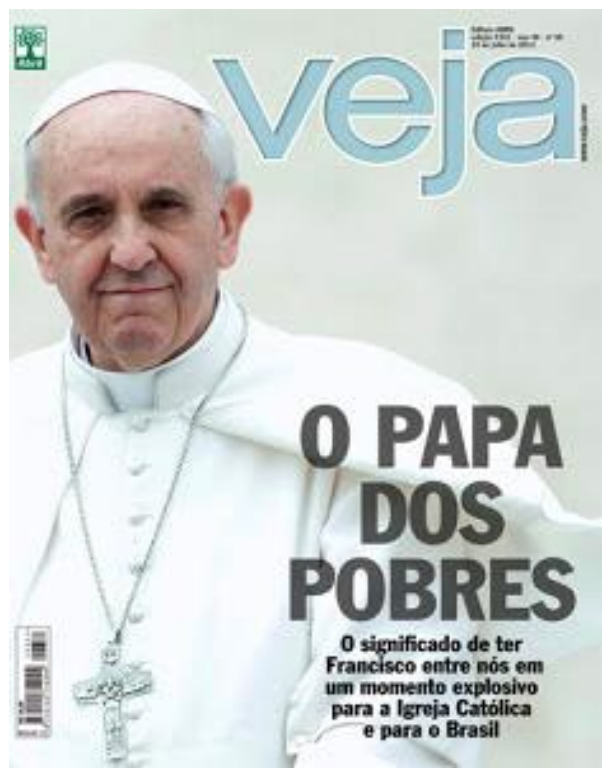

Na SD4 aparece um contraste, pois se "este" papa só é dos pobres é porque os anteriores não são. Esse processo reforça o efeito de "novidade", que por sua vez é aquilo que a mídia deseja e constantemente busca (ou fabrica): acontecimentos espetaculares que atraem muitos leitores e vendas.

O enunciado em questão sobre o "momento explosivo" remete aos escândalos como os de pedofilia e lavagem de dinheiro. Isso seria um dos sinais de desgaste da Igreja "antiga" que o papa Francisco viria a "reformar".

A igreja é antiga também em valores relativos ao âmbito de seu código moral. A Igreja Católica é uma instituição que sempre lutou em favor de valores considerados tradicionais. Ela é contra o casamento dos padres, bem como não aceita a homossexualidade. O papa tem discutido abertamente esses valores, chamando os membros da Igreja e até os laicos a se posicionarem sobre assuntos como: o celibato dos padres, a relação da Igreja com a homossexualidade (aceitar ou não e etc.). Esses aspectos também dão um tom de acontecimento discursivo tanto ao que se enuncia sobre o papa, quanto ao que lhe é atribuído como tendo dito.

Essa maneira de o sujeito enunciador mobilizar os escândalos da Igreja católica (momento explosivo) é marcado linguisticamente pelo "entre nós"; esta marca linguística indicia uma segregação entre quem segue o código moral à risca e quem vai de encontro a este, produzindo uma divisão: o "nós" e o "eles".

Esta divisão também remete à memória da ladainha professada nos cultos como a missa "ele está entre nós". Nas missas, esse enunciado se refere geralmente ao Salvador Jesus, e seu aparecimento, aqui, desloca essa memória investindo o papa Francisco no papel de Salvador, como veremos na análise mais adiante.

Notamos o potencial de acontecimento discursivo e também de espetacularização que "momento explosivo" traz para a capa da revista e para a matéria de capa como um 
todo. O significante "explosivo" sustenta o efeito de um possível desastre de grandes proporções, bem ao gosto sensacionalista de parte da mídia, e que chama muito a atenção. O significante "momento" cria para o leitor a impressão de estar vendo a história acontecer ressaltando a grandiosidade desse momento que seria diferente dos outros.

A figura 5, capa da revista Família Cristã, ano 79 - abril de 2013 No 928, traz nossa SD5, a qual dá sustentação a essa interpretação de que o novo papa (e seu "papado" recém-iniciado) seria incomparável aos anteriores, apresentando o papa como fato novo e "sem igual".

\section{Figura 5 - SD5: "Francisco: para um mundo onde sobram diferenças: um papa sem igual"}

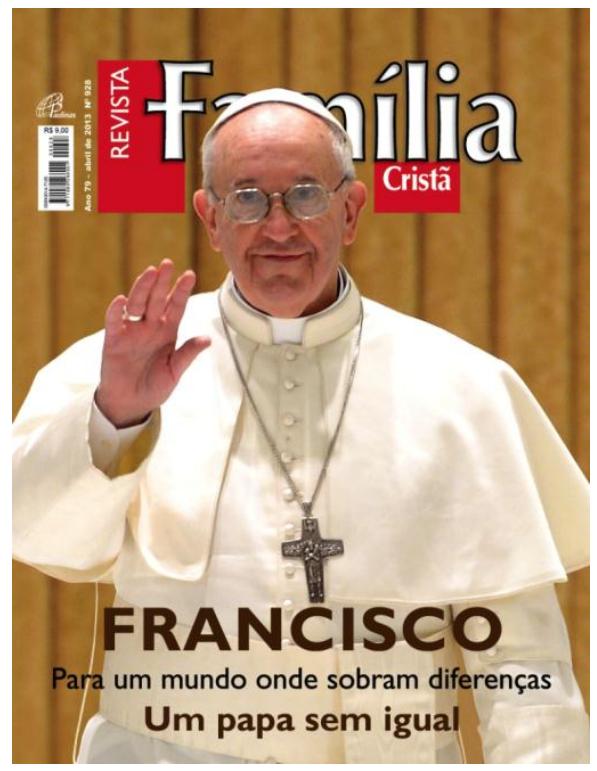

Esta sequência discursiva da capa faz um jogo com os significantes "diferenças" e "igual", que remetem diretamente a uma região da memória discursiva segundo a qual a Igreja Católica teria um discurso para os "ricos" e os "pobres". E que teria um papel na regulação e na reprodução do status quo social, enquanto Aparelho Ideológico de Estado (ALTHUSSER, 1999); e isto é feito administrando, a partir deste lugar discursivo, o papel dos ricos e dos pobres, na terra e no céu. Isso remete ao discurso presente nas SDs 3 e 4 sobre o "papa do povo" e o "papa dos pobres".

Esse jogo de significantes toma os termos "diferenças" e "igual", retirando-os do contexto da regulação dos ricos e pobres e recoloca esses termos com foco na figura do papa (no caso "sem igual": único). Isso tem um efeito de espetacularização do papa e da sua figura (uma iconização do papa) e que contribui também para uma leitura de acontecimento discursivo, de rompimento com o passado.

Essa iconização levada a cabo tanto pela mídia em geral quanto pela mídia católica pode ser vista como efeito de uma sociedade que valoriza as assim chamadas "celebridades", que seriam pessoas que aparecem e que tem muita visibilidade. Se a sociedade capitalista se desenvolveu em meio a uma ideologia que valoriza o indivíduo, no capitalismo tardio e pós-moderno em que vivemos, o culto à personalidade se torna 
parte da cultura com o que poderíamos chamar de "cultura das celebridades". Disto decorre outro efeito de sentido; vejamos: As personalidades em geral não precisam de conteúdo para aparecer (não é o caso do papa Francisco). Podemos também lembrar que o termo "ícone" faz parte dos discursos da igreja tanto no sentido das figuras como os mártires, beatos e santos que adornam as Igrejas, como no sentido da adoração de falsos deuses.

Na SD6, que aparece na figura 6, capa da revista The Advocate de dezembro de 2013, chama a atenção o uso do marcador "If", o que mobiliza uma discussão a partir da interface proposta por Pêcheux (1993) entre a noção de pré-construído e o efeito de evidência sustentado no silogismo.

\section{Figura 6-SD6: "If someone is gay and seeks the Lord with good will, who am I to judge?"}

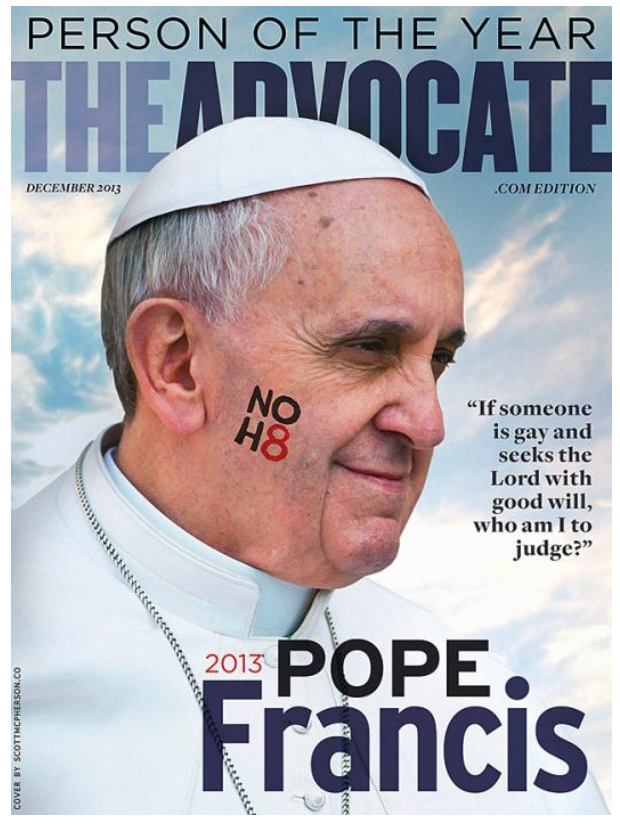

O enunciado em questão na SD6 é tratado como parte da novidade ou do acontecimento discursivo do novo papado nesta linha vista na SD4, que trata de assuntos polêmicos para a Igreja católica dando a esses temas uma nova "orientação" no sentido de que a Igreja estaria mudando sua posição e seu tratamento em relação a temas como a homossexualidade. Nesse sentido, o acontecimento discursivo desse papado não pode ser tratado sem um cotejo com seu discurso, um discurso que parece ser de rompimento com alguns princípios ou práticas da Igreja já assentados há muito tempo.

Em $\mathrm{AD}$, concebemos as imagens também enquanto discursos; assim, notamos que a imagem da capa traz como que uma tatuagem colorida no rosto do papa (NOH8), que leríamos como "No hate" e que traduziríamos como "sem ódio", ou "não ao ódio". Tratase de uma referência ao discurso de que o novo papa teria uma posição diferente, ou seja, de rompimento com a posição homofóbica, de ódio à homossexualidade assumida até então pela Igreja. 
Para Courtine (2013), a articulação de imagens entre si é a expressão do valor icônico destas e da forma de nossa sociedade compartilhar a memória coletiva. O material significante destas imagens é indício de um depósito de outras imagens, que também significam alhures o que já foi dito de outra maneira em outro lugar.

A tatuagem do papa se relaciona também com o efeito de novidade, de acontecimento discursivo e de rompimento na medida em que constrói a imagem de um papa moderno, "antenado" com o mundo contemporâneo, diferentemente dos papas anteriores, pois, como sabemos, a tatuagem hoje é algo que está na moda, e que, ao mesmo tempo, o preconceito social em relação à tatuagem diminuiu muito hoje em dia. Além disso, a tatuagem na face do papa seria mais uma pista (GINZBURG, 2003) de que o papa é pop, ou seja: de que sua imagem é moderna, e circula bem no mundo visual da atualidade.

Pêcheux (1993) trata da questão nominal no pré-construído em termos da "articulação de enunciados, implicação de propriedades, efeito de sustentação (p. 105)". Esta articulação é feita em um misto de silogismos e relativas, muitas vezes.

No caso analisado, temos o uso da partícula "se" como marcadora de uma contingência em aberto acerca de uma suposição de que o lugar discursivo do Papa pode ou não julgar moralmente alguém. Poderíamos escandir este marcador da seguinte forma:

“Se A é B e C, quem sou para julgá-lo?” Esta formulação dá conta do percurso de uma fórmula silogística, do todo para a parte e vice-versa. No silogismo, poderíamos escrever: Todo A é B; C é A; logo, C é B. Deste modo, cria-se um efeito de negação da interpretação, de tal modo que a evidência de que o papa julga alguém é aparentemente retirada pela questão final: quem sou eu para julgar? A relação entre "papa" como figura genérica e que faz parte do todo da formulação lógica e o uso do pronome "eu", tal como aparece na formulação, indica um efeito paradoxal de "exclusão" da categoria mais ampla da qual o enunciado depende para se sustentar. Um efeito semelhante pode ser visto na SD7, a qual aparece na capa do informativo diocesano, da Diocese de Umuarama-PR, ano 40, No 412, fevereiro de 2015:

$\mathrm{Na}$ SD7 podemos ler o seguinte silogismo: "Todos os papas querem uma Igreja tranquila; Francisco é papa; Logo, Francisco quer uma Igreja tranquila”. Temos aí uma quebra de expectativa sustentada pela negação da conclusiva da fórmula silogística, que se supõe ser evidente por conta do efeito de obviedade do silogismo está na substituição de "tranquila" por "missionária". Mas qual a relação de dois termos díspares utilizados aparentemente no mesmo nível da formulação, em termos da memória e do acontecimento discursivo?

Uma das questões a se discutir na substituição de "tranquila" por "missionária" se relaciona à perda de fiéis, pois outras Igrejas (não católicas) fazem uma espécie de "corpo a corpo" com os fiéis, passando de porta em porta, conversando com os moradores, deixando santinhos, panfletos, livretos, nas casas. 


\section{Figura 7 - SD7: "Eu não quero uma Igreja tranquila. Quero uma Igreja missionária!"}

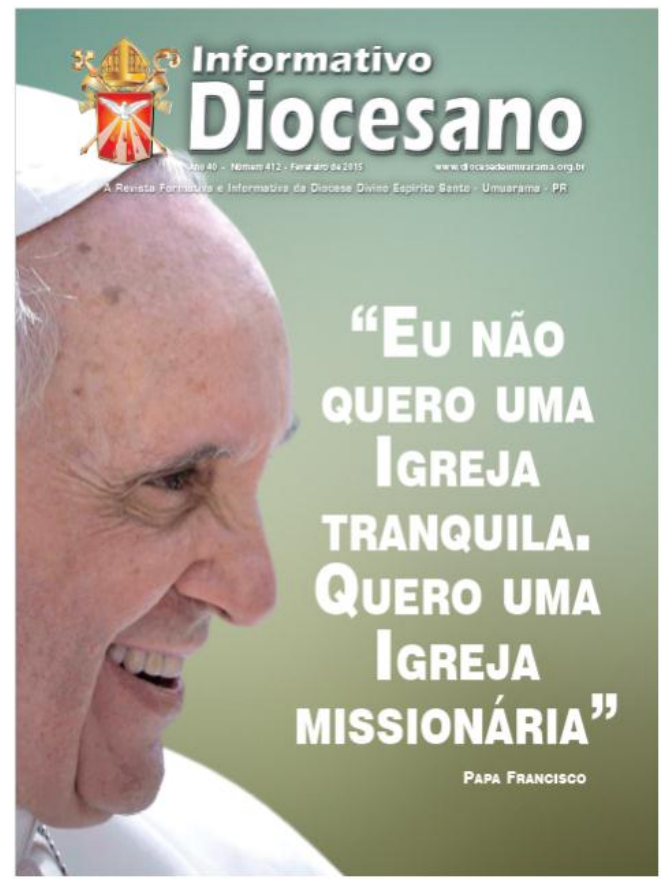

As Igrejas também têm atraído fiéis através da mídia, usando a televisão, a internet e redes sociais. Vale lembrar que a Igreja Católica também aderiu a esses métodos para ampliar sua influência e reduzir o movimento de perda de fiéis. Isso indica uma consciência da importância do uso espectáculo por essas organizações. No Brasil a Igreja Católica criou seu canal de televisão nesse rastro. Sabemos que o Vaticano tem, há muito tempo, uma rádio de alcance mundial, e que, recentemente, aderiu à rede social da web denominada Facebook, também utilizando o recurso da mídia nessa disputa pelos fiéis. Por isso, a Igreja Católica, e os padres, não poderiam mais ficar parados esperando os fiéis dentro dos templos. Seria preciso fazer o mesmo "corpo a corpo" de outras Igrejas.

Isso está ligado à mudança entre o papado do cardeal Ratzinger (Bento XVI) e o novo, de Francisco. O papado anterior buscava uma Igreja mais "autêntica", mais ligada aos valores da tradição católica, e não via com bons olhos uma "Igreja à la carte" na qual o fiel escolheria como agir: se iria a missa ou não, por exemplo. Nesse sentido, era um papado que não se preocupava se a Igreja tinha muitos fiéis ou não. A preocupação era com a doutrina. O papado atual pode ser considerado um papado que acolhe, e essa preocupação é que faz com que a Igreja "vá para a rua" (trataremos desse enunciado adiante) e seja missionária.

A oposição entre essas duas nomeações merece destaque, uma vez que o enunciado marca um efeito de "ou X (...) ou Y". Em outras palavras, ou a Igreja é "missionária" ou "é tranquila". É impossível ser ambas as coisas ao mesmo tempo. Esse plano da impossibilidade sustenta a formação imaginária em questão, ao nível do Esquecimento $\mathrm{N}^{\mathrm{o}} 2$ proposto por Pêcheux (1993), uma vez que a transversalidade do discurso requer a mobilização de um efeito de reformulação que se organiza por meio da substituição de "tranquila" por "missionária". 
Para isto, faz-se necessário mobilizar lugares da memória do dizer em que, por exemplo, resgatam-se histórias da participação da Igreja Católica ligada às Cruzadas, à Reforma Protestante e à Contra-Reforma ou mais recentemente aos movimentos sociais e políticos da América Latina. Em relação ao esquecimento número dois visto em Pêcheux (1993), podemos analisar o efeito de não dito entre o uso do verbo "querer" e sua regência que demanda um objeto direto. Do ponto de vista sintático, a substituição de um substantivo por um adjetivo marca um efeito do nível do esquecimento dois, em relação ao controle da interpretação. No lugar temos a adjetivação "tranquila" e "missionária".

Portanto, no caso da SD6 temos uma Igreja em tese mais verdadeira (mais coerente com essa memória sobre a tradição católica) "se missionária", ou menos verdadeira "se tranquila". Há uma permissividade na zona de sentidos do interdiscurso que permite ambas as nomeações, entretanto, organizadas conforme o jogo com o impossível.

O efeito de impossibilidade no uso de "não tranquila" e "missionária" é sustentado pela exclusão acima mencionada, bem como pelo sentido dominante de que para ser missionária a marca pessoal é fundamental.

Na Figura 8, capa da revista Veja $\mathrm{N}^{\mathrm{o}} 2332$, de Julho 2013, temos a SD8:

\section{Figura 8 - SD8: PAPA FRANCISCO NO BRASIL: "Quero que a Igreja vá para as ruas"}

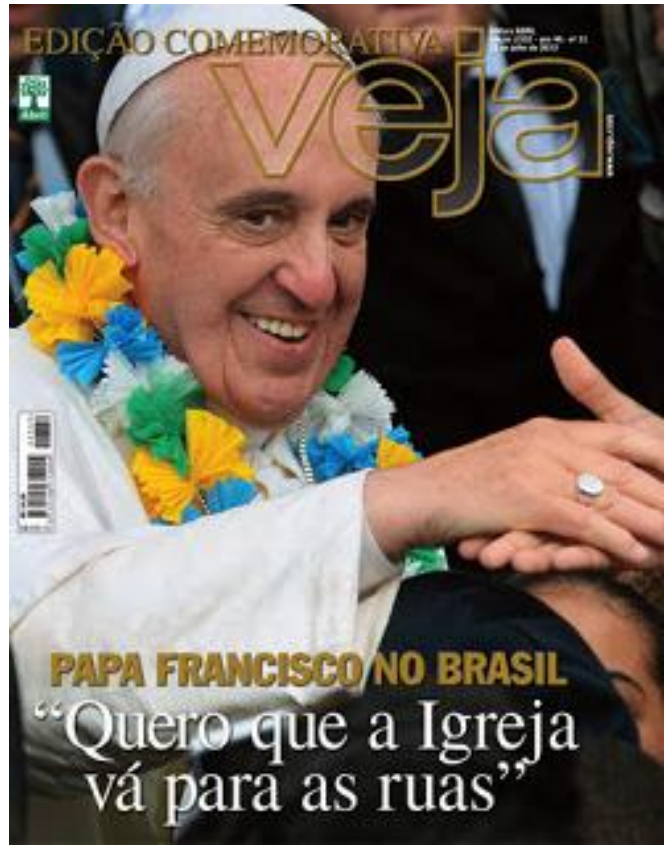

A SD8 sugere (para o leitor brasileiro) a migração do slogan "vem pra rua" proferido nas manifestações de rua ocorridas em junho de 2013 no Brasil. Cabe perguntar: trata-se do acontecimento discursivo pêcheutiano? O modo como a formulação aparece faz notar um fragmento atribuído ao sujeito-papa, mas proferido do lugar do texto jornalístico. Este deslocamento é marcado pelo uso do discurso direto por meio das aspas. Há uma aparente estabilidade semântica no uso deste slogan quando na verdade trata-se 
de um jogo de forças. Levantada aqui como hipótese analítica (ACHARD, 1999), ela nos indica uma forma de o implícito atuar em um lugar memorizado do imaginário. Do passado recente, exige-se do sujeito-leitor uma mobilização do enunciado "vem pra rua". Como nos lembra Achard (1999), não podemos provar a autonomia de um enunciado, mas podemos interpretá-lo por relações de contingência em que sua reconstrução depende de formas inseridas por paráfrase.

Sobre o acontecimento discursivo, é justamente na indagação sobre os limites de sustentação da paráfrase sob a égide de um lugar no imaginário afetado pelo simbólico que se abrem as questões sobre sua relação com a memória; para Pêcheux (1999) questões ligadas ao escape à inscrição e à absorção na memória.

Há um lugar do imponderável, do incontornável que clama por um modo de evidência do funcionamento dos sentidos, modo este que mobiliza o acontecimento histórico de junho de 2013 pelo qual a imagem do sujeito-papa desloca a memória sóciohistórica recente para tornar visível e nomear outro fato, e isto é feito, conforme Pêcheux (1999), de modo a torná-lo visível. Esta é uma função da memória para Pêcheux (1999): mobilizar implícitos para uma leitura e esta leitura, como aponta o autor ao retomar Achard (1999), depende de mobilizar uma série legível, podendo ser entendida também como modo de evidência ideológica; no caso, mobilizada ao sustentar várias narrativas desdobráveis a partir de um marcador ("vem pra rua") e, a partir deste ponto tornadas possíveis, de acordo com paráfrases ligadas ao domínio de memória do sujeito-papa"nova" Igreja Católica.

Neste deslocamento, temos algo da ordem do acontecimento discursivo, pois outro efeito de organização das sequências é do plano de um efeito de sentido em que se tem uma espécie de "recitação de um mito" (expressão retirada de Pêcheux (1999)); ou seja, permite como que tornar automático um dizer repetitivo, tal como uma ladainha a respeito do que já se saberia sobre a relação entre Igreja Católica e um suposto Estado laico. Deste modo, o deslocamento "vá para as ruas" indica "várias" Igrejas indo para "vários lugares" e de "vários modos"; no entanto, esta indefinição se sustenta num já sabido acerca de uma laicidade suposta, porém não ocorrida de fato.

Este efeito discursivo de paráfrase de um slogan cujo sentido dominante é assegurado pelo modo de o sujeito poder ocupar um lugar deslocado na cadeia discursiva indica outro lugar da memória discursiva, em que se tem a dúvida, o vacilo, a hesitação na assertiva sobre a laicidade do Estado.

Deste ponto, vale perguntar: Qual a relação entre o sujeito-papa e poder político? Qual a relação que se estabelece entre a Igreja católica e o poder político, por meio desses cruzamentos entre formulações e memória discursiva, através de imagens e manchetes jornalísticas? Qual o valor do determinante político sedimentado pela ideologia? Afinal, o Estado é mesmo laico? Vejamos na SD9, como estas formulações assim dispostas sustentam uma trama dos sentidos. Na figura 9, temos a SD9 da revista Veja de 27 de março de $2013 \mathrm{~N}^{\mathrm{o}} 2314$ : 
Figura 9 - SD9: À sombra do papa. A fé e o carisma de Francisco conquistaram o coração do povo - e sua influência na política da América Latina será uma bênção

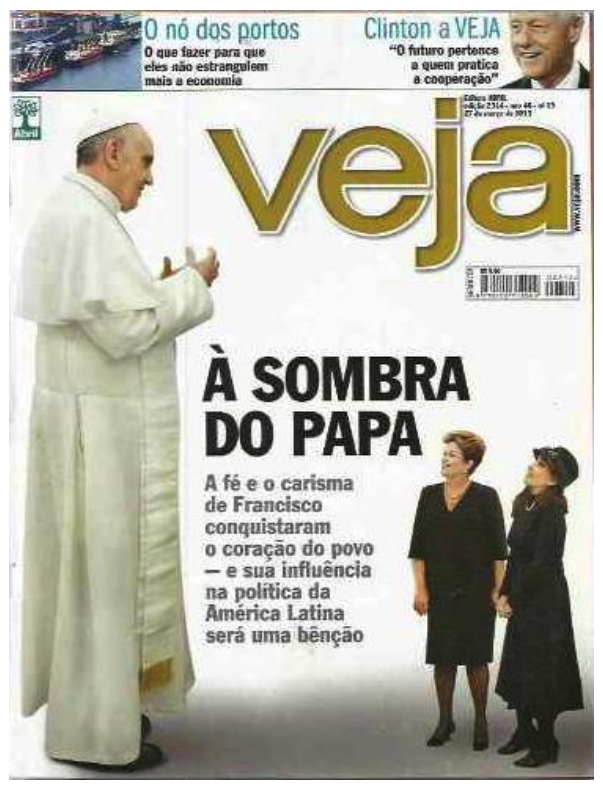

A imagem desta capa da Veja mostra duas governantes da América Latina com vestimentas de beatas, vestidas de preto e aos pés do papa. Vemos marcada uma posição na política que faz referência a muito do que apontamos acima. A relação entre imagem e visibilidade de um acontecimento discursivo, no caso, pode ser analisada pela contingência estabelecida entre "fé", "carisma", "influência política" e "bênção".

O leitor familiarizado com as discussões travadas nos trabalhos de análise do discurso, na mídia e nas redes sociais sabe que a revista Veja tem uma posição contrária à das presidentes Dilma e Cristina Kirchner, então, a imagem da capa procura diminuir e até ridicularizar as presidentes e ao mesmo tempo enaltecer o papa Francisco; esse efeito é obtido pela diminuição das duas em tamanho, colocadas ao lado do papa em tamanho bem maior. Isso reforça a influência da Igreja sobre o Estado, mas, não a um Estado qualquer, um Estado que é governado por figuras às quais a revista Veja se opõe. A posição da Veja aparece também na SD9, na qual a revista faz a apologia da influência política do papa sobre os governos Dilma e Cristina Kirchner, é o que lemos no trecho: "e sua influência na política da América Latina será uma bênção".

A capa acima lida com um dos aspectos tratados como centrais na modernidade, que seria a separação entre Estado e Igreja Católica (COELHO NETO, 1986). No período medieval, não havia separação entre ambos, de modo que o poder político era exercido pela Igreja Católica. Na modernidade, haveria uma separação entre Igreja e Estado, de modo que a Igreja não teria influência na política. A capa mostra uma Igreja que tem sim influência na política, desmentindo o tratado da modernidade.

Além disso, as chefes de Estado estão vestidas de preto da cabeça aos pés como se fossem "beatas" a seguir o papa, o que reforça a leitura de que a Igreja tem influência no Estado e na política. Vemos o crescimento disso por todo o mundo: Nos Estados Unidos, 
temos Estados proibindo (ou tentando proibir) o ensino de evolução e substituindo-o pelo ensino do criacionismo. No Oriente Médio, as propostas de instalação da lei divina no lugar de um estado laico. E, para finalizar, vale lembrar que Althusser (1999) afirma que a Igreja é um Aparelho Ideológico do Estado. Isso indica que Estado e Igreja não estão separados e que trabalham em conjunto para atingir objetivos comuns, como a reprodução da dominação social pelos grupos dominantes. Numa linguagem foulcaultiana (FOUCAULT, 2013), poderíamos dizer que Estado e Igreja estão juntos com o objetivo de produzir "corpos uteis e dóceis".

Chama a atenção, portanto, o modo como estes termos cujos sentidos são dados ao sujeito-leitor a partir de uma marca de obviedade em sua mobilização, são contrastados com o uso de um verbo no passado e outro no futuro, a saber: "A fé e o carisma conquistaram" e "a influência política será uma bênção".

Trata-se de um efeito de sentido que sugere a aproximação com pessoas comuns, uma marca na memória talvez do modo como o populismo esteve presente nos governos da América Latina. Deste modo podemos tratar de um deslizamento entre "popularidade" e "populismo" criando efeitos de sentido.

Considerado como marca típica dos governos Vargas e Goulart no Brasil (FONSECA; MONTEIRO, 2005), o populismo traz dificuldades de consenso conceituais por conta do conturbado período histórico dos dois governos, mas com fator comum de ações econômicas vacilantes e hesitantes, entre propostas desenvolvimentistas e taxas inflacionárias em aceleração.

Gomes (1998) aponta a polarização entre poder central e local que caracterizou esta primeira metade do século XX na tentativa de equilibrar poder público e privado e modernizar politicamente um país patriarcal, por meio da neutralização do personalismo que ameaçava a unidade do poder no espaço público. Disso resultam as medidas de caráter econômico e trabalhista autoritária e corporativista que engrandece uma figura máxima, popular, supostamente redentora.

O presidente é esta figura máxima e centralizadora do Estado, um executivo afeito aos interesses populares, interesses estes lidos sob a óptica do próprio presidente, interferindo inclusive nos sindicatos. Em suma, um "corporativismo democrático" para "organização do povo brasileiro" (expressões da autora, idem) de forma que o "corporativismo" no poder público junto da carnavalização dos interesses privados tornaram o "populismo" uma forma de "tradução do impasse a ser vencido para a conquista da modernidade política, que se entendia, mais uma vez, traída e desvirtuada". Portanto, o populismo não é simples engano das massas e somente "mascaramento" de conflitos políticos; é mais complexo, pois "é tanto uma forma de controle sobre as massas, como uma forma de atendimento de suas reais demandas" (GOMES, 1998, p.502).

Esse papel de liderança do papa aparece também na figura 10 capa da revista Época de 22 de Julho de 2013 na qual temos nossa SD10: 
Figura 10 - SD10: Reportagem especial. 10 LIÇÕES DE VIDA DO PAPA. A humildade de Francisco ilumina a todos nós - e seu exemplo inspira o Brasil em crise. A pompa e a modéstia na história do catolicismo. Os riscos para a segurança durante a visita papal. "Francisco é uma mudança radical no caminho da Igreja"

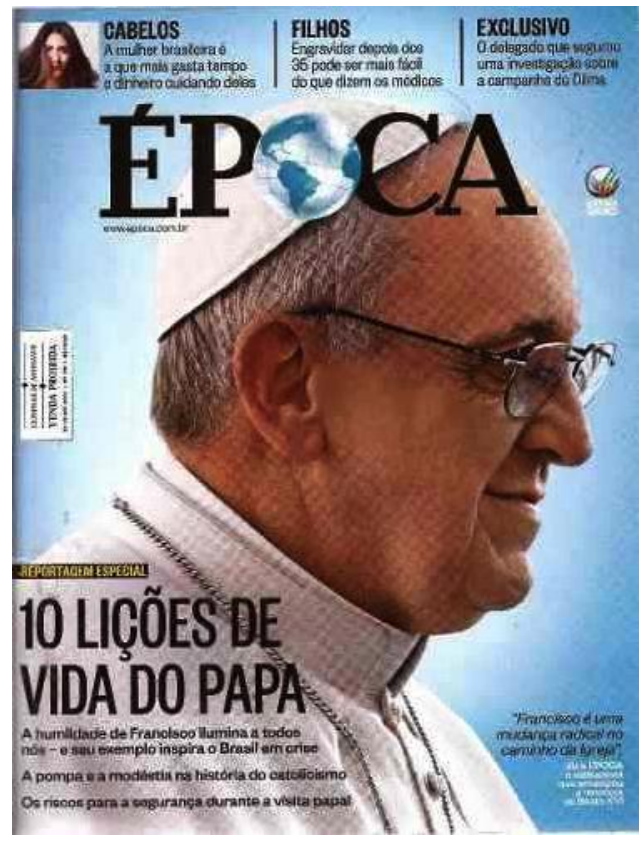

Notamos a atribuição de sentidos sobre o sujeito-papa significado como uma "mudança radical nos caminhos da Igreja". Notamos que "mudança radical" aponta para uma imagem de acontecimento histórico notável.

A SD10 possui um aspecto de livro de autoajuda. Isso pode ser lido e interpretado nas "10 lições de vida do papa". A capa fala também de termos como "humildade", inspira, modéstia e ilumina, que podem ser lidos, num cotejo com as 10 lições mencionadas, o que significaria que entre as lições do papa, teríamos lições de humildade e modéstia que inspirariam e iluminariam o leitor. Chiaretti (2013) mostrou que o efeito paradoxal dos livros de autoajuda reservam um lugar para a subjetividade que deve ser exemplar ao mesmo tempo em que organizado discursivamente por uma orientação utilitária e reveladora de um caminho supostamente mais verdadeiro.

Do ponto de vista do domínio da memória discursiva temos também um efeito de sentido de liderança que inclui a referência a uma zona de sentidos, cuja atualidade de memória resgata delimita o efeito de "manager", "chefe executivo" como aparece no jargão das organizações privadas de trabalho. Como temos um líder religioso, essa liderança pode se revestir em tons proféticos ou de um salvador.

Temos aí uma aliança com o efeito de sentido delimitado pela evidência ideológica de que um líder é um líder porque gerencia algo. Trata-se de um lugar da memória que evoca o self made man no qual temos uma aliança com os discursos de autoajuda, uma vez que a liderança é atribuída a uma pessoa empírica.

Além disso, temos o sentido implícito de que "quem dá aos pobres empresta a Deus", marcado pela atribuição de que o lugar do sujeito-papa contrasta "pompa" e 
"modéstia" na Igreja Católica. O funcionamento implícito do genérico acima pode ser destacado como parte de um silogismo: "Toda religião é honesta e humilde. A Igreja Católica é uma religião. Logo, a Igreja (que é católica) é honesta e humilde". Trata-se de um modo de confrontar determinativas e explicativas tal como Pêcheux (1993) indica ser um dos caminhos para a análise das paráfrases pela mobilização do pré-construído e da articulação em meios aos discursos transversos. Neste caso "a Igreja que é católica é honesta e humilde".

Vemos também aí a presença de um discurso pedagógico, pois o discurso pedagógico não existe apenas na escola (ver TFOUNI; ASSOLINI, 2007), mas pode estar em todo discurso onde se instalam suas características como: a irreversibilidade, o autoritarismo (ver ORLANDI, 1987).

Uma das pistas (GINZBURG, 2003) para isso seria o significante "lições" no enunciado da capa, de modo que o papa assumiria nesse discurso o lugar do professor ou do mestre, aquele que tem autoridade para falar e para ensinar sobre certo assunto. $\mathrm{O}$ leitor assume aqui o lugar do aluno pronto para aprender. Para a Igreja Católica o papa é a maior autoridade nas questões metafísicas do espírito e da alma. Por isso ele estaria mais que autorizado a falar sobre como o fiel deveria e poderia conduzir sua vida para levá-la a contento.

No discurso pedagógico tradicional, por sua vez, o lugar discursivo do professor assume a figura do cientista (ver ORLANDI, 1987) e sua palavra se reveste de verdade, não podendo ser questionada na medida em que é a palavra da ciência. No discurso religioso o papa não precisaria disso. Basta lembrar que a religião não se apoia na "verdade" e sim no dogma. Ao mesmo tempo, a Igreja tem afirmado que reconhece a ciência e até mesmo que se apoia nela. Por exemplo, o processo de canonização de alguma figura, e seus alegados milagres precisam passar por um crivo científico para provar que não se trata de algo natural e, sim, sobrenatural. Vemos, então, um cruzamento dos discursos religioso e pedagógico nessa capa.

Com o enunciado sobre "lições de vida do papa" vemos que o papa daria, então, lições de vida aos leitores e fiéis. Isso permite uma leitura segundo a qual eles não sabem como viver, estariam perdidos. Em meio ao discurso pedagógico presente neste modo de sustentar efeitos de sentido, a memória do discurso religioso também é mobilizada em torno do enunciado comumente vulgarizado no cotidiano "o senhor é meu pastor". No discurso religioso, cabe às figuras religiosas como padres, bispos, e o papa, conduzir as pessoas (seu rebanho de ovelhas) no caminho da vida, pois elas não o fariam sozinhas (não saberiam fazer?). O Papa aparece aí como aquele vai dar o norte, que vai dar o caminho para fiéis e leitores perdidos. Notamos que Forbes (2010) propõe que o sujeito de hoje é um sujeito "desbussolado", sem norte, sem rumo. Diríamos então que a Igreja se tornaria esteio desse sujeito perdido no mundo pós-moderno. Esta seria uma das motivações do recrudescimento dos movimentos religiosos especialmente após a queda do muro de Berlim. Inclusive, quando estava crucificado, Jesus teria dito "perdoe-os pai, eles não sabem o que fazem", ou seja, eles precisam ser conduzidos, pelo pastor, para o caminho correto. 
Adiante, o efeito de sentido com o uso da nomeação "o santo dos pobres" permitenos continuar a discussão sobre este lugar da memória discursiva na SD11, que está na figura 11, capa da edição 2313 de 20 de março de 2013 da revista Veja:

\section{Figura 11 - SD11: PAPA FRANCISC0. 0 profundo e histórico significado da escolha do nome do Santo dos Pobres pelo novo líder espiritual dos católicos}

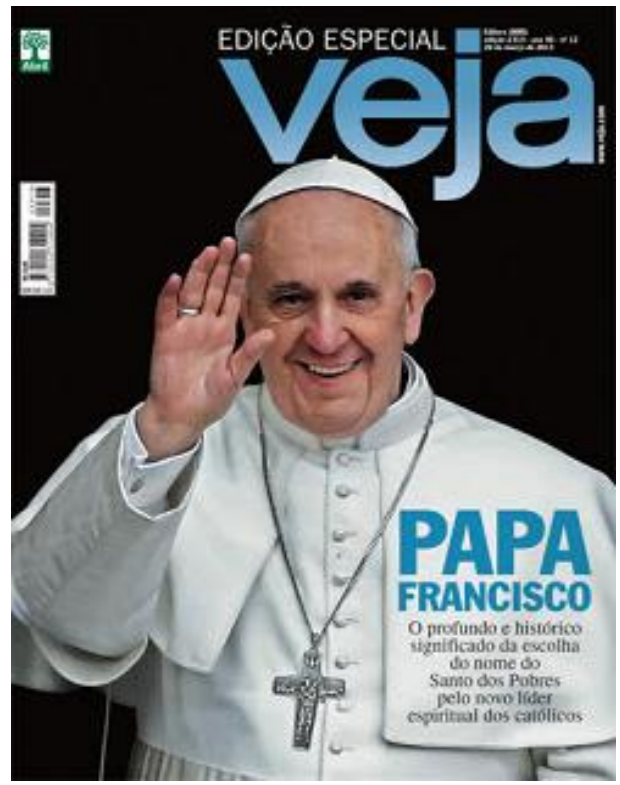

Na SD 11, ao nível do implícito, temos que "Santo dos pobres" substitui o nome "Francisco" (no caso, São Francisco). Num procedimento de deslizamento metafórico, pontuamos a metáfora "Santo dos Pobres" como forma deslocada de falar sobre "pobreza". Em meio à memória do populismo aqui evocada, temos um modo de referirse à memória que traz o contraste entre "pompa" e "humildade". Em outras palavras, é o nome "Santo dos Pobres" (que evoca "pobreza") que indicia a suposta revelação do significado "profundo e histórico" do nome escolhido, uma vez que em meio aos sentidos de "profundidade" não se diz o que não se pode dizer já na capa da revista, mas indicase, por meio da formação imaginária em questão, que o sujeito-leitor já sabe algo a respeito da "surpresa" da nomeação, pois espera-se uma Igreja de "pompa".

Nesse sentido, a SD11 dialoga as SDs 3 e 4, que enunciam e anunciam o "papa do povo" e o "papa dos pobres”. Cronologicamente, a SD11 é anterior às SDs 3 e 4, porém não levamos em conta a cronologia, mas o aspecto dialógico e intertextual. Aqui, vemos a intertextualidade realizando um efeito de reforço, que se relaciona também com a repetição dos sentidos. A repetição (INDURSKY, 1997) é importante discursivamente na medida em que não basta uma enunciação; é a reiteração dessa enunciação é que vai transformar isso num discurso. A SD11 reitera também o papa como líder, reforçando e dialogando com o que já apareceu na SD10. É em meio a este efeito de retorno e de circulação dos sentidos que as marcas do acontecimento discursivo em torno da figura papal é enunciado pela mídia. 
Através do corpus coletado e da análise, notamos que o discurso das capas de revista em questão trata o papa Francisco como uma grande novidade que deverá mudar os rumos da Igreja Católica. Nesse sentido, a escolha do novo papa tem sido tratada como um acontecimento, no sentido forte do termo, pela imprensa.

Alguns motivos para isso seriam dados logo de saída, independentemente do resultado do seu papado, como, por exemplo: Francisco é o primeiro papa da América Latina, ele foi escolhido para substituir um papa que renunciou, o que é um fato histórico, porque a última renúncia de um papa foi há mais de 1200 anos.

Todavia, se pensarmos o acontecimento discursiva como uma mudança profunda dentro da Igreja em termos de uma mudança de regras, dogmas, da doutrina ou da liturgia, sabemos que essa mudança não depende do papa sozinho, pois se, como sabemos, ninguém governa sozinho, ela depende do grupo de cardeais que agora está no poder.

Essa é uma das questões em torno da figura do papa: a mídia parece tratá-lo como um príncipe (Maquiavel) que governaria sozinho. Essa imagem é bem assentada na nossa memória, afinal, a sociedade capitalista sempre buscou um "salvador da pátria", ou messias ou herói que vai liderar as massas (no caso os fiéis) rumo a uma mudança para dias melhores e que traduz um patamar de sucesso.

Como tudo recai sobre a figura do papa, a mídia o trata como "personalidade do ano", como pessoa a ser notada, num culto à personalidade que se aproxima da "cultura das celebridades", numa sociedade do espetáculo, sendo ele (o papa) o personagem principal e, talvez, único desse acontecimento tratado como show pela mídia.

A eficácia deste "show" reside no caminho aqui apontado, em que um lugar do visível é apenas parte de um efeito de sentidos, em que apontamos um feixe de ícones, plurais e heterogêneos, mas versados na "mesma" figura; o que não apaga, no plano da alteridade, vários lugares possíveis de serem lidos, entre os implícitos restabelecidos pela memória e o acontecimento, lido como marca do político, em que a novidade faz apelo à esfera do pessoal, remexendo a popularidade e o populismo.

Finalizando, podemos dizer que os sentidos veiculados pela mídia sobre o papa, no que tange ao recorte aqui trazido, são sentidos positivos, de apreciação, e de esperança. Como nosso corpus é um recorte, e há muito conteúdo sobre o papa Francisco na mídia, este artigo não pretende ser a leitura definitiva dos discursos sobre o papa Francisco na mídia, e nem poderia ser assim, já que a análise o os sentidos mobilizados numa análise dependem em parte da posição ocupada pelo analista na leitura e interpretação do corpus.

\section{REFERÊNCIAS}

ACHARD, P. Memória e produção discursiva do sentido. P. ACHARD et al. (Org.) Papel da memória. Campinas/SP: Pontes. 1999. 11-17.

ALTHUSSER, L. Ideologia e Aparelhos Ideológicos de Estado. In: ŽIŽEK, S. (Org.). Um mapa da ideologia. Rio de Janeiro: Contraponto. 1. reimpr., 1999.

CHARAUDEAU, P. Discurso das mídias. São Paulo: Contexto, 2007. 
CHIARETTI, P. Subjetividade e discurso em livros de autoajuda. Tese (Doutorado em Psicologia), Programa de Pós-graduação em Psicologia, Universidade de São Paulo, Ribeirão Preto-SP, 2013.

COELHO NETO, J. T. Moderno pós-modeno. Porto Alegre: L\&PM editores, 1986.

COURTINE, J.-J. Corpo, discurso, imagens: entrevistas. In: COURTINE, J.-J. Decifrar o corpo: pensar com Foucault. Petrópolis/RJ: Vozes, 2013. p. 11-46.

DEBORD, G. A sociedade do espetáculo. Rio de Janeiro: Contraponto, 9. reimpr., 2007.

FONSECA, P.C.D.; MONTEIRO, S.M.M. Credibilidade e populismo no Brasil: a política econômica dos governos Vargas e Goulart. Rev. Bras. Econ., Rio de Janeiro, v. 59, n. 2, jun. 2005. Disponível em <www.scielo.br>. Acesso em: 16 set. 2014. <http://dx.doi.org/10.1590/S0034-71402005000200004>.

FORBES, J. Psicanálise do homem desbussolado. Revista Psique, n. 53. 2010. Disponível também em: <http://www.jorgeforbes.com.br/br/artigos/psicanalise-do-homem-desbussolado-artigo-psique.html> Acesso em: 15 out. 2013.

FOUCAULT, M. Vigiar e punir: nascimento da prisão. Rio de Janeiro: Vozes, 2013.

GINZBURG, C. Sinais: raízes de um paradigma indiciário. In: Mitos, emblemas, sinais: morfologia e história. 2. ed., 1. reimpr. São Paulo: Companhia das Letras, 2003.

GOMES, A.C. A política brasileira em busca da modernidade: na fronteira entre o público e o privado. In.: L. M. SCHWARCS (Org.). História da vida privada no Brasil: contrastes da intimidade contemporânea, vol. 4. São Paulo/SP: Cia. das Letras, 1998. p. 489-558.

HAROCHE, C. O comportamento de deferência: do cortesão à personalidade democrática. Tradução de J. A. Seixas. História: Questões \& Debates, Curitiba, n. 42, p.115-139, 2005.

INDURSKY, F. A fala dos quartéis e as “outras vozes”. Campinas/SP: EdUNICAMP,1997.

Lula lá: estrutura e acontecimento. Organon, Porto Alegre, v. 17, n. 35, p. 101-121, 2003.

ORLANDI, E. P. A linguagem e seu funcionamento. Campinas/SP: Pontes. 1987.

. As formas do silêncio: no movimento dos sentidos. 3. ed. Campinas, SP: Ed. UNICAMP, 1995.

Discurso: fato, dado, exterioridade. In: M. F. P. CASTRO (Org.). O método e o dado no estudo da linguagem. Campinas/SP: Ed. da UNICAMP, 1996. p. 209-219.

. Análise de Discurso: princípios e procedimentos. 4. ed. Campinas, SP: Pontes, 2002.

PÊCHEUX, M. Semântica e Discurso: uma crítica à afirmação do óbvio. 2. ed. Campinas/SP: UNICAMP, 1993.

Discurso: Estrutura ou acontecimento? Campinas: Pontes, 1997.

Papel da memória. In: P. ACHARD et al. (Org.). Papel da memória. Campinas/SP: Pontes, 1999.

RASSI, A, P. Do acontecimento histórico ao acontecimento discursivo: uma análise da "Marcha das vadias". Revista História, Goiânia, v.1, n.1, p. 43-63, jan./jun. 2012.

SERRANI, S.M. Um método para estudar a discursividade na abordagem de questões socioculturais. In:

. A linguagem na pesquisa sociocultural: um estudo da repetição na discursividade. Campinas/SP:

Ed. da UNICAMP, 1997. p. 53-71.

TFOUNI, L. V.; ASSOLINI, F. E. Letramento e trabalho pedagógico. Revista Eletrônica Acolhendo a Alfabetização nos Países de Língua Portuguesa, São Paulo, v. 1, n. 1, p. 36-58, 2007. Disponível em: <http://www.revistas.usp.br/reaa/article/view/11446> Acesso em 01 fev. 2016.

VINCENT, G. Os católicos: o imaginário e o pecado. In.: A. PROST; G. VICENT (Org.). História da Vida Privada: da Primeira Guerra a nossos dias. 2. ed. 5. reimpr. São Paulo/SP: Companhia das Letras. 1997. p. 393-425.

\section{REFERÊNCIAS DO CORPUS COLETADO}

Figura 1: Revista Rolling Stone do dia 13 de fevereiro de 2014 Disponível em: <http://abcnews.go.com/blogs/headlines/2014/01/pope-francis-rocks-rolling-stone-magazine-cover/> Acesso em: 01 fev. 2016.

Figura 2: Revista Time, edição de 23 de novembro de 2013. Disponível em: <http://content.time.com/time/covers/0,16641,20131223,00.html> Acesso em: 01 fev. 2016. 
Figura 3: Revista Time do dia 29 de julho de 2013. Disponível em <http://p2.trrsf.com/image/fget/cf/images.terra.com/2013/07/22/capatimepapareprod.jpg> acesso em: 01 fev. 2016.

Figura 4: Capa da Revista Veja No 2331, de Julho de 2013. Disponível em: <http://veja.abril.com.br/acervodigital/home.aspx>. Acesso em: 01 fev. 2016.

Figura 5: Capa da revista Família Cristã, ano 79 - abril de 2013 № 928. Disponível em: <http://www.paulinas.org.br/familia-crista/?system=news\&action=read\&id=3815> Acesso em: $01 \mathrm{fev}$. 2016.

Figura 6: <http://www.advocate.com/year-review/2013/12/16/advocates-person-year-pope-francis>. Acesso em: 01 fev. 2016.

Figura 7: Capa do informativo diocesano, da Diocese de Umuarama-PR, ano 40, No 412, fevereiro de 2015. Disponível em: 〈https://docs.google.com/file/d/0B74LzkX-8sUqbXV1eDNzYzRtcHM/edit>. Acesso em: 01 fev. 2016.

Figura 8: Capa da revista Veja $\mathrm{N}^{\circ}$ 2332, de Julho 2013. Disponível em: <http://veja.abril.com.br/acervodigital/home.aspx>. Acesso em 01 fev. 2016.

Figura 9: Capa da Revista Veja da edição 2314 de 27 de março de 2013. Disponível em: <http://veja.abril.com.br/acervodigital/home.aspx>. Acesso em 01 fev. 2016.

Figura 10: Capa da revista Época da edição 791 de 22 de Julho de 2013. Disponível em: <http://epoca.globo.com/colunas-e-blogs/faz-caber/noticia/2013/07/qual-capa-voce-escolheria.html>. Acesso em 01 fev. 2016.

Figura 11: Capa da Revista Veja capa da edição 2313 de 20 de março de 2013. Disponível em: <http://veja.abril.com.br/acervodigital/home.aspx>. Acesso em 01 fev. 2016.

\section{Recebido em: 03/06/15. Aprovado em: 25/10/15.}

Title: Between event and memory: discourses about Pope Francis in large circulation magazine covers

Authors: Fabio Elias Verdiani Tfouni; Anderson de Carvalho Pereira

Abstract: This work carries out an analysis of the discourses about Pope Francis on the cover of large circulation magazines, both national and from abroad. Specifically we discuss if the choice of the new Pope may be considered as an event in the terms defined by the French tradition of discourse analysis. The concepts of event and memory are used here side by side, because the event has a relation with the memory. We argument that the meaning effects created about the new Pope is related to its characterization as an event. We also discuss that the media constructs and transforms this event into a spectacle. Other concepts like interpretation, pedagogical discourse and populism are also discussed.

Keywords: Event. Memory. Discourse. Media. Pope Francis.

Título: Entre el acontecimiento y la memoria: discursos sobre el papa francisco en cubiertas de revista de circulación masiva

Autores: Fabio Elias Verdiani Tfouni; Anderson de Carvalho Pereira

Resumen: Este trabajo realiza un análisis de los discursos sobre el Papa Francisco en cubiertas de revistas nacionales e internacionales de circulación masiva. Discutimos si la elección del nuevo papa, y los discursos adviniéndoos de ella pueden ser considerados acontecimientos. Trabajamos la cuestión del acontecimiento relacionando con la memoria, como es propio del Análisis del Discurso de Pêcheut. Argumentamos que los efectos de sentido creados sobre el nuevo papado se relacionan con su caracterización como un acontecimiento. También analizamos el cambio que la media hace del Papa y otros aspectos en un espectáculo, como la cuestión de la interpretación del discurso pedagógico e da relación con el populismo.

Palabras-clave: evento. Memoria. Discurso. Medios de Comunicación. Papa Francisco. 